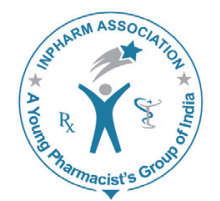

JIP

\title{
Experimental Design for the Optimization of Nanoscale Solid Lipid Particles Containing Rasagiline Mesylate
}

\author{
Viveksarathi Kunasekaran and Kannan Krishnamoorthy* \\ Department of Pharmacy, Faculty of Engineering and Technology, Annamalai University, Annamalai \\ Nagar-608 002, Tamil Nadu, India.
}

\begin{abstract}
Background: The objective of this investigation was to design and optimize the fabrication of Rasagiline mesylate loaded nanoscale solid lipid particles composed with stearic acid as lipid matrix by microemulsion technique. Rasagiline ( $\mathrm{N}$-propargyl1-R-aminoindan) mesylate (RM) is a potent, selective, irreversible inhibitors of monoamine oxidase-B, propargylaminebased drug. It has been explored in the treatment of Parkinson disease. Nanoscale solid lipid particles are the exploited carrier system for targeted drug delivery in a controlled manner. Method: The Plackett-Burman design was successfully employed for the optimization of nanoscale solid lipid particles containing Rasagiline mesylate. The influence of independent variables studied were lipid, surfactant and co-surfactant concentration, volume of aqueous phase, magnetic stirring rate, probe sonicator duration, volume of beaker used and volume of cold aqueous phase. The dependent variables, namely average particle size, span, surface area and polydispersity index of the formulated Rasagiline mesylate loaded solid lipid nanoparticles. Results: The experiments were carried out according to 12 runs involving 8 independent variables (higher and lower levels) employing Plackett-Burman design. The Rasagiline mesylate-loaded solid lipid nanoparticles were characterized by average mean particle size, span, surface area and polydispersity index and it results were $169 \mathrm{~nm}$, $0.821,52.4 \mathrm{~m}^{2} \mathrm{~g}^{-1}$ and 0.310 , respectively. The morphological evaluation of optimal Rasagiline mesylate loaded solid lipid nanoparticles was found to be monodisperse, uniform size and quasispherical shape with smooth surface by transmission electron microscopy (TEM). The selected area electron diffraction (SAED) indicated the formulation was not in an amorphous form but in a crystalline state. Conclusion: The experimental results were good correlated with predicted data analysed by Plackett-Burman statistical method.
\end{abstract}

Key words: Plackett-Burman, Rasagiline mesylate, Ransmission electron microscopy, Selected area electron diffraction, Solid lipid nanoparticles.

\section{INTRODUCTION}

Rasagiline (N-propargyl-1-R-aminoindan) mesylate (RM) is a potent, selective, irreversible inhibitors of monoamine oxidase- $\mathrm{B}$, propargylamine-based drug. It

\begin{tabular}{|c|c|}
\hline \multicolumn{2}{|c|}{ Access this article online } \\
\hline Journal Sponsor & \multirow[b]{2}{*}{$\begin{array}{l}\text { Website: } \\
\text { www.jyoungpharm.org }\end{array}$} \\
\hline & \\
\hline & $\begin{array}{l}\text { DOI: } \\
\text { 10.5530/jyp.2015.4.2 }\end{array}$ \\
\hline
\end{tabular}

has been explored in the treatment of Parkinson disease. ${ }^{1}$ The existing research of Rasagiline mesylate and its analogues are under investigation for Alzheimer disease. Despite its rapid absorption and reaching peak plasma concentration in approximately 1 hour, the bioavailability after oral administration is $36 \%$ with short elimination half-life $(0.6-2 \mathrm{hrs}){ }^{2} \mathrm{RM}$ is metabolized to its major metabolite aminoindan. ${ }^{3}$ Parkinson disease (PD) is the second most common progressive neurodegenerative disorders in the world and it manifested clinically by motor symptoms, including rigidity, resting tremor and

\footnotetext{
*Address for correspondence:

Dr. Kannan Krishnamoorthy, Department of Pharmacy, Faculty of Engineering and Technology, Annamalai University, Annamalai Nagar-608 002, Tamil Nadu, India.E-mail: egkkannan@yahoo.co.in
} 


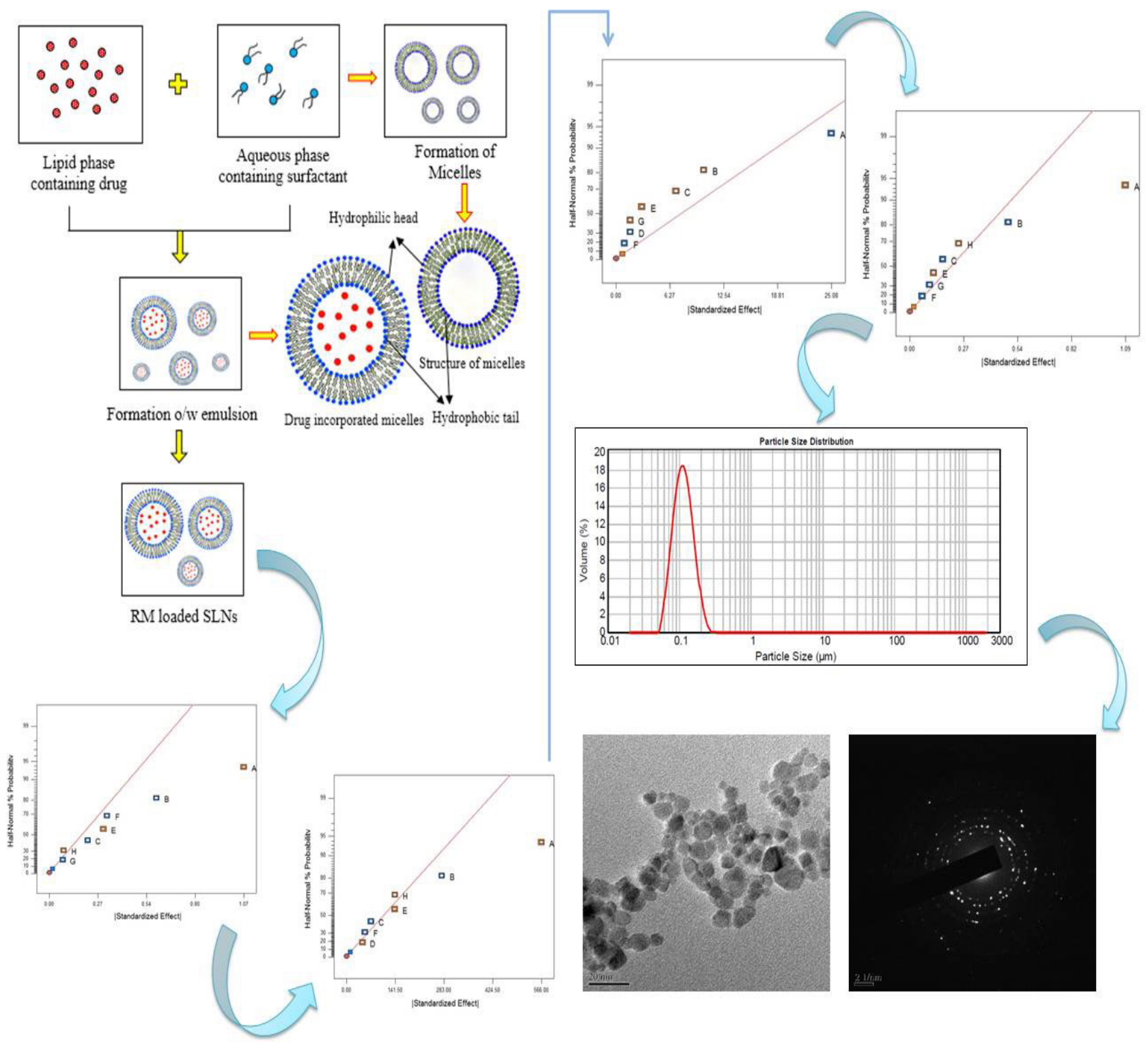

Graphical Abstract

bradykinesia in the limbs followed by postural instability. ${ }^{4}$ $\mathrm{PD}$ is characterized by selective loss of melanin-containing dopaminergic neurons within the substantia nigra (pars compacta) of the ventral midbrain region. ${ }^{5}$ The resulting of dopamine deficiency in the striatum causes disinhibition and overactivity of the subthalamic nucleus (STN). ${ }^{6}$ The treatment of Parkinson disease is limited by the insufficiency in delivering therapeutic drugs into the brain. The major problem with delivery of drugs into the brain is the presence of the blood brain barrier (BBB). Only small molecules with high lipophilic and low molecular weight (400-500 Da) drugs able to across the blood brain barrier.? A variety of novel approaches have been implemented to over come this problem which includes blood-brain barrier disruption, biological drug delivery, chemical drug delivery systems, magnetic drug targeting, liposomes, polymeric nanoparticles and solid lipid nanoparticles. Among these nanoscale solid lipid particles become an important area of research in the field of drug delivery into brain in a sustained period of time. ${ }^{7,8}$ Nanoscale solid lipid particles are the exploited carrier system for targeted drug delivery in a controlled manner of the pharmaceutical research. In recent years, this colloidal carrier system possesses distinct advantages and excellent tolerability compared liposomes and other polymeric nanoparticles. ${ }^{9}$ Moreover, the fabrication of procedure can be modulated for desired drug release, protection of drug degradation and avoidance of organic solvents. ${ }^{10}$ Numerous techniques for nanoscale solid 
lipid particle fabrications exist. The common approaches consist in high pressure homogenization, hot/cold homogenization, microemulsion, solvent emulsification, solvent evaporation, solvent diffusion, double emulsion, ultrasonication technique, solvent emulsification-diffusion method, supercritical fluid technology, spray drying and solvent injection technique. ${ }^{11-13}$ However, we have selected microemulsion technique, as it the thermodynamically stable, most expedient and economical technique to fabricate nanoscale solid lipid particles. ${ }^{14-16}$

The objective of this study was to fabricate the nanoscale lipid particles by microemulsion technique and evaluate the effects of different formulation and processing parameters on the characteristics RM-SLNs. A statistical model viz. Plackett-Burman design was used for identification of important components influential in the fabrication of nanoscale lipid particle characteristics such as particle size, span, surface area and poly dispersity index.

\section{MATERIALS AND METHODS}

\section{Materials}

Rasagiline mesylate was obtained from Orchid health care Pvt Ltd, Chennai, India as gift sample. Stearic acid, Poloxamer 407 and Tween 80 were purchased from Sigma Chemical Labs, Bangalore, India. The analytic grade chemicals and reagents were used for all the experiments. Double distilled water was used after filtration through a $0.45 \mu \mathrm{m}$ membrane (cellulose acetate).

\section{Methods}

\section{Plackett-Burman experimental design}

The development of RM-SLNs process includes, many preparation variables appear to have a noticeable influence on the formulation characteristics (average particle size, span, surface area and poly dispersity index). The formulation characteristic can be acceptance limits with proper optimized preparation variables. Evaluating the effect of many preparation variables usually requires many experiments, which are often expensive and time consuming. Consequently, prudent to minimize the total number of experiments done in the optimization process, without sacrificing the quality of prepared RM-SLNs. ${ }^{17}$ The process and formulation can be understood by using numerous statistical designs of experiments. However, we have preferred Plackett-Burman design (PBD), which has been frequently used for screening the large number of factors and identifying the critical one in a minimal number of runs with good degree of accuracy. In PBD, the main effect of each variable was calculated as. ${ }^{18,19}$

$$
E_{x i}=2\left(\Sigma H_{x i}-\Sigma L_{x i}\right) / N
$$

Where, $\mathrm{E}_{\mathrm{xi}}$ is the particular variable main effect, $\Sigma \mathrm{H}_{\mathrm{xi}}$ is the summation of response value at the higher level, $\Sigma \mathrm{L}_{\mathrm{xi}}$ is the summation of response value at the lower level and $\mathrm{N}$ is the number of trials. A main effect figure with a negative sign indicates an inverse relationship between that particular variable, while a positive sign indicates the effect that favors the optimization. The linear equation of Plackett-Burman design is as follows. ${ }^{20-23}$

$$
Y=b_{0}+b_{1} X_{1}+b_{2} X_{2}+b_{3} X_{3}+b_{4} X_{4}+b_{5} X_{5}+-+b_{n} X_{n}
$$

Where, $\mathrm{Y}$ is the response, $\mathrm{b}_{0}$ is the constant and $\mathrm{b}_{1}, \mathrm{~b}_{2} \ldots \mathrm{b}_{\mathrm{n}}$ are the coefficient of variables $\mathrm{X}_{1}$,

$\mathrm{X}_{2} \ldots \mathrm{X}_{\mathrm{n}}$ (representing the effect of each variable ordered within -1, +1).

\section{Optimization and statistical analysis}

Based on preliminary experiments and on literature, the influence of independent variable parameters selected were lipid $\left(\mathrm{X}_{1}\right)$, surfactant $\left(\mathrm{X}_{2}\right)$, and co-surfactant concentration $\left(\mathrm{X}_{3}\right)$, aqueous phase volume $\left(\mathrm{X}_{4}\right)$, magnetic stirrer rate $\left(\mathrm{X}_{5}\right)$, probe sonication duration $\left(\mathrm{X}_{6}\right)$, volume of beaker used for sonication $\left(X_{7}\right)$, volume of cold aqueous phase $\left(\mathrm{X}_{8}\right)$ on the dependent variables such as average particle size $\left(\mathrm{Y}_{1}\right)$, span $\left(\mathrm{Y}_{2}\right)$, surface area $\left(\mathrm{Y}_{3}\right)$ and polydispersity index $\left(\mathrm{Y}_{4}\right)$ of the formulated Rasagiline mesylate loaded solid lipid nanoparticles (Table 1). Other parameters, i.e., magnetic stirrer rate and probe sonicator duration were not having a significant impact on particle size and their levels were kept constant for all the experiments. Magnetic stirrer rate has an impact on particle size and was included in the design.

\begin{tabular}{|cccc|}
\hline \multicolumn{4}{c}{ Table 1: Experimental factors and their values } \\
\hline Factor & Factor significance & Level (-) & Level (+) \\
\hline $\mathbf{X}_{1}$ & Lipid concentration $(\mathrm{mg})$ & 50 & 150 \\
$\mathbf{X}_{2}$ & Surfactant Concentration $(\mathrm{mg})$ & 25 & 75 \\
\hline $\mathbf{X}_{3}$ & Co-surfactant Concentration $(\mathrm{ml})$ & 0.25 & 0.75 \\
$\mathbf{X}_{4}$ & Volume of aqueous phase $(\mathrm{ml})$ & 5 & 15 \\
\hline $\mathbf{X}_{5}$ & Magnetic Stirrer rate $(\mathrm{rpm})$ & 200 & 400 \\
\hline $\mathbf{X}_{6}$ & Probe sonicator duration $(\mathrm{min})$ & 10 & 30 \\
\hline $\mathbf{X}_{7}$ & Volume of beaker used probe & 125 & 250 \\
$\mathbf{X}_{8}$ & $\begin{array}{c}\text { Volume of clod aqueous phase } \\
(\text { ml) }\end{array}$ & 30 & 50 \\
\hline
\end{tabular}




\section{Preparation of RM loaded SLNs}

RM loaded solid lipid nanoparticles were fabricated by microemulsion technique. Briefly, the lipid phase containing stearic acid was melted above its melting point. Rasagiline mesylate was added in the melted lipid. The surfactant (Poloxamer 407) and Co-surfactant (Tween 80) were dissolved in $10 \mathrm{ml}$ of aqueous phase. The lipid phase was added drop-wise to aqueous phase and then subjected to magnetic stirring at $300 \mathrm{rpm}$ for $15 \mathrm{mins}$. The obtained o/w microemulsion was dispersed in cold water under probe sonicator for 20 mins. $^{15,16}$

\section{Evaluation of RM loaded SLNs}

The fabricated Rasagiline mesylate solid lipid nanoparticles particle size, span and surface area were carried by dynamic light scattering (DLS), also known as photon correlation spectroscopy (PCS) or quasi-elastic light scattering (QELS), which records the variation in the intensity of scattered light on the microsecond time scale by using Malvern Mastersizer 2000 MS device (Malvern Instruments, Worcestershire, UK) and laser diffraction with a beam length of $2.40 \mathrm{~mm}$, range lens of $300 \mathrm{RF} \mathrm{mm}$, at $10.14 \%$ obscuration. The sample was diluted with double distilled water and then the sample was added drop by drop into sample holder for measurement.

Polydispersity index was calculated from the width of the particle size of distribution by using the equation $=\mathrm{D}(0.9)$ $\mathrm{D}(0.1) / \mathrm{D}(0.5)$. Where, $\mathrm{D}(0.9), \mathrm{D}(0.5)$ and $\mathrm{D}(0.1)$ are corresponding to particle size immediately above $90 \%$, $50 \%$ and $10 \%$ of the sample. The measuring range of the Malvern Mastersizer is from $0.02 \mu \mathrm{m}$ to $2000 \mu \mathrm{m} .{ }^{24,25}$

Polydispersity index value below 0.3 shows the narrow sized distribution, which is the most significant parameter that decides the uniformity of nanoparticle performance such as solubility, drug release, dissolution, cellular uptake. However, the higher Polydispersity index value $(<0.3)$ indicates a higher heterogeneity in particle size distribution..$^{21,26}$

\section{Transmission electron microscopy (TEM)}

The surface morphology of Rasagiline mesylate loaded solid lipid nanoparticles was examined by transmission electron microscopy (TEM) using JEOL JEM-2000 EXII TEM (Tokyo, Japan). The samples were negatively stained with $0.5 \%(\mathrm{w} / \mathrm{v})$ phosphotungstic acid solution for 30 and fixing on coated copper grids with carbon film and dried under vacuum pressure. Furthermore, a selected area electron diffraction (SAED) pattern is recorded to determine the nature of the particles.

\section{RESULT AND DISCUSSION}

\section{Mechanism of a microemulsion method to produce solid lipid nanoscale particles}

The fabrication of Rasagiline mesylate loaded solid lipid nanoparticles intended was tailored as per the microemulsion technique described in the previously published literature. ${ }^{15}$ This experiment pacts with the mechanism of solid lipid nanoparticles fabrication by microemulsion technique and the principle behind with the incorporation of Rasagiline mesylate into these nanoparticulate systems. Based on the preliminary studies, stearic acid, tween 80 (polyethoxylated sorbitan) and poloxamer 407 (polypropylene glycol and polyethylene glycol) were chosen as lipid, surfactant and co-surfactant respectively. A molten stearic acid (lipid), which contain drug (Rasagiline mesylate), is contacted with a mixture consisting water, a surfactant and co-surfactant. The obtained $\mathrm{o} / \mathrm{w}$ microemulsion is dispersed in water of 2 to $10^{\circ} \mathrm{C}$. The hydrophilic surfactant will require a cosurfactant to form an o/w microemulsion. Co-surfactant plays an important role in the formation of microemulsion and it helps the surfactant to reduce the interfacial tension to very low values to achieve the thermodynamic stability. When the surfactant and co-surfactant are mixed together the micelle is formed (Figure 1). The micelles consist of a hydrophilic core compartmentalized by the hydrophilic head group in aqueous phase and the hydrophobic tail group has dissolved in lipid phase. Consequently, when the lipid phase was introduced in aqueous phase, a number of possible loci were available in the spherical micelles and the drug might be located either in the palisade layer or in the inner core of the micelle.

\section{Screening of parameters using Plackett-Burman design}

Plackett-Burman design was applied to screen out the positive factors contributing to the fabrication of Rasagiline mesylate loaded solid lipid nanoparticles. This experiment was conducted in twelve runs involving seven independent variables were generated by Design-Expert ${ }^{\circledR}($ Version 7.1.5; Stat-Ease, Inc. USA). The experimental design results revealed that this system was highly inclined by the amount of lipid and lipid/surfactant concentration, which resulted in maximum surface area and small particle sizes for fabrication of Rasagiline mesylate loaded solid lipid nanoparticles.

\section{Effect of preparation variables on formulation characteristics}

By using the microemulsion technique, several experimental responses were assessed in order to achieve the optimal fabrication conditions, including particle size, span, 


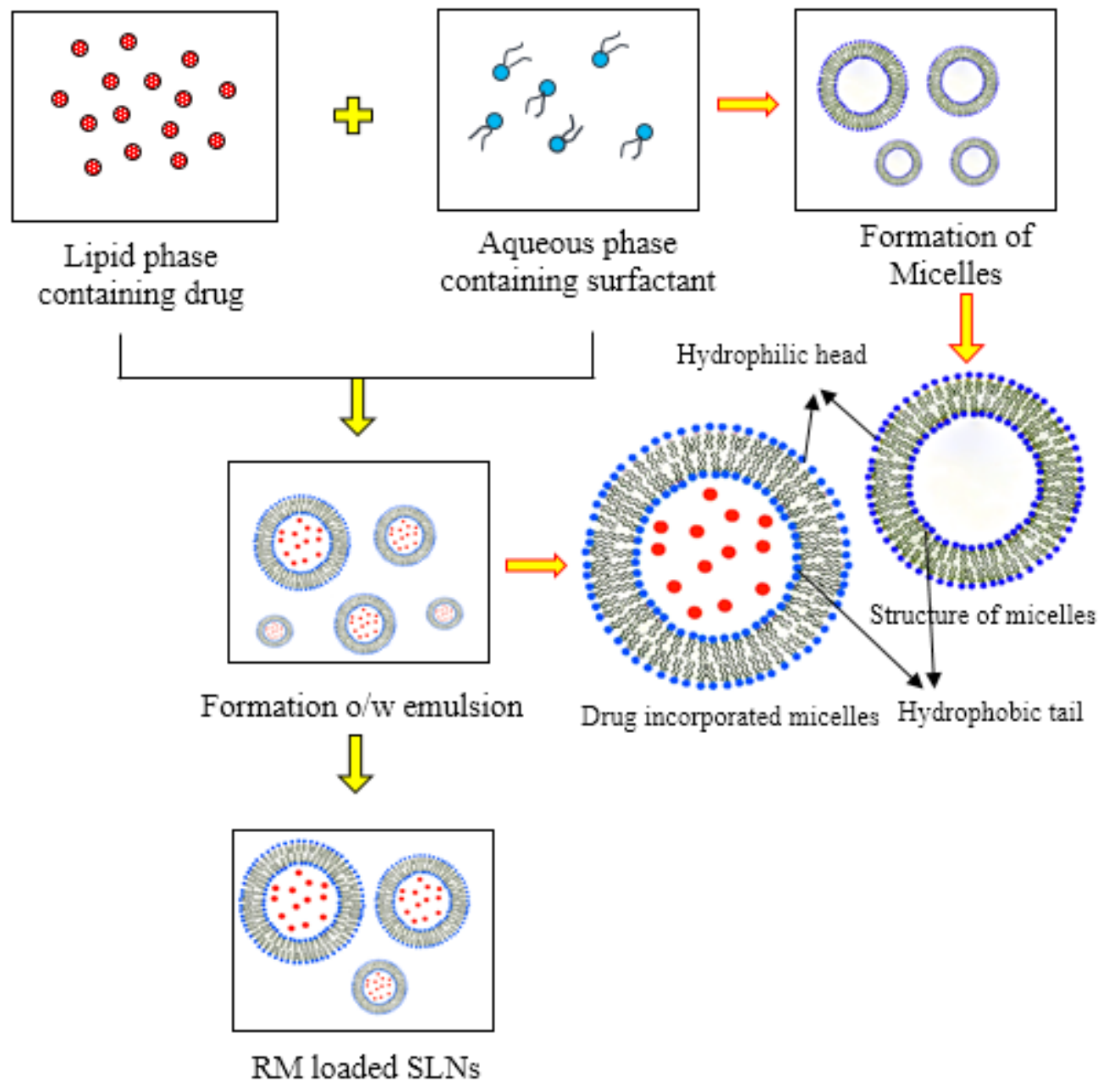

Figure 1: Schematic diagram of formulation of Rasagiline mesylate loaded solid lipid nanoparticles prepared by microemulsion method

surface area and poly dispersity index. The results of these experiments were compared using analysis of variance (ANOVA), which was able to determine if the factors and the interactions between factors were significant.

\section{Effect of Formulation Variables on Particle Size}

Solid lipid nanoparticles have been extensively investigated in the field of pharmaceutical research and the particle size of SLNs can play an important role as it can instantly influence the physical stability, cellular uptake, biodistribution and the drug release. Be contingent on the desired administration route, the size of the particle should be optimized. The Particle size range 10 to $1000 \mathrm{~nm}$ is acceptable for intravenous administration. ${ }^{27-30}$ Following linear model equation can describe the $\mathrm{Y}_{1}$ [Average particle size $=+480.83+283.00 * \mathrm{~A}-138.33 * \mathrm{~B}-35.33 * \mathrm{C}+23.17$ $* \mathrm{D}+69.83 * \mathrm{E}-26.67 * \mathrm{~F}+70.17 * \mathrm{H}$ ] (Table 2). The F-value of the model 560.10 implies that the model is significant and the Values of "Prob > F" less than 0.0500 indicate model terms are significant. The predicted $\mathrm{R}^{2}(0.9633)$ and adjusted $R^{2}(0.9980)$ values implied a good correlation between the obtained and predicted value and those of the fitted models (Table 3). The Particle size distribution of Rasagiline mesylate loaded solid lipid nanoparticles was revealed in (Figure 2). The small particle size of 169 $\mathrm{nm}$ could be achieved by working the experiment under following experimental conditions, lipid concentration of $50 \mathrm{mg}$, surfactant concentration of $75 \mathrm{mg}$, Co-surfactant concentration of $0.75 \mathrm{ml}$, aqueous phase volume of 5 $\mathrm{ml}$, magnetic stirring speed of $400 \mathrm{rpm}$, probe soniation duration 30 mins, volume of beaker used for sonication $500 \mathrm{ml}$ and volume of cold aqueous phase $30 \mathrm{ml}$. Increase in particle size $\left(\mathrm{Y}_{1}\right)$ was observed to increase in lipid concentration $\left(\mathrm{X}_{1}\right)$ and as well decrease the probe sonicator duration $\left(\mathrm{X}_{2}\right)$. The value of the coefficient of variation (CV) is $3.84 \%$ and indicates the precision and reliability of the model. The half normal plot results indiactes (Figure $3)$, the lipid concentration, volume of the aqueous phase, magnetic stirring rate and volume of cold aqueous phase 
Table 2: Design of Independent and dependent variables chart

\begin{tabular}{|c|c|c|c|c|c|c|c|c|c|c|c|c|}
\hline \multirow[b]{2}{*}{ Trials } & \multicolumn{8}{|c|}{ Independent variables } & \multicolumn{4}{|c|}{ Dependent variables } \\
\hline & $X_{1}(\mathrm{mg})$ & $X_{2}(m g)$ & $\mathrm{X}_{3}(\mathrm{ml})$ & $\mathrm{X}_{4}(\mathrm{ml})$ & $X_{5}($ rpm $)$ & $x_{6}(\min )$ & $\mathrm{X}_{7}(\mathrm{ml})$ & $\mathrm{X}_{8}(\mathrm{ml})$ & $\begin{array}{c}\text { Average } \\
\text { Particles } \\
\text { size } \\
(\mathrm{nm})\end{array}$ & Span & $\begin{array}{c}\text { Surface } \\
\text { Area } \\
\left(\mathrm{m}^{2} \mathrm{~g}^{-1}\right)\end{array}$ & $\begin{array}{c}\text { Poly } \\
\text { dispersity } \\
\text { index }\end{array}$ \\
\hline 1 & 50 & 25 & 0.25 & 5 & 200 & 10 & 125 & 30 & 239 & 1.325 & 32.9 & 0.478 \\
\hline 2 & 50 & 25 & 0.25 & 15 & 200 & 30 & 250 & 30 & 224 & 1.128 & 34.1 & 0.408 \\
\hline 3 & 150 & 75 & 0.75 & 5 & 200 & 10 & 125 & 30 & 248 & 1.341 & 30.2 & 0.438 \\
\hline 4 & 50 & 75 & 0.75 & 5 & 400 & 30 & 250 & 30 & 169 & 0.821 & 52.4 & 0.31 \\
\hline 5 & 50 & 75 & 0.75 & 15 & 200 & 10 & 250 & 50 & 175 & 0.834 & 50.7 & 0.225 \\
\hline 6 & 50 & 75 & 0.25 & 15 & 400 & 10 & 250 & 50 & 184 & 0.983 & 47.5 & 0.198 \\
\hline 7 & 150 & 75 & 0.25 & 15 & 400 & 30 & 250 & 30 & 556 & 1.625 & 21.3 & 0.853 \\
\hline 8 & 150 & 25 & 0.75 & 15 & 200 & 30 & 250 & 50 & 857 & 1.853 & 14.6 & 1.504 \\
\hline 9 & 150 & 75 & 0.25 & 5 & 200 & 30 & 125 & 50 & 723 & 1.924 & 17.1 & 1.619 \\
\hline 10 & 150 & 25 & 0.25 & 5 & 400 & 10 & 125 & 50 & 1171 & 2.947 & 14.7 & 1.974 \\
\hline 11 & 50 & 25 & 0.75 & 5 & 400 & 30 & 125 & 50 & 196 & 0.993 & 46.2 & 0.251 \\
\hline 12 & 150 & 25 & 0.75 & 15 & 400 & 10 & 125 & 30 & 1028 & 2.821 & 15.4 & 1.906 \\
\hline
\end{tabular}

$\mathbf{X}_{1}$ : lipid concentration, $\mathbf{X}_{2}$ : surfactant concentration, $\mathbf{X}_{3}$ :co-surfactant concentration, $\mathbf{X}_{4}$ : volume of aqueous phase, $\mathbf{X}_{5:}$ magnetic stirrer rate, $\mathbf{X}_{6}$ : probe sonication duration, $\mathbf{X}_{\mathbf{7}}$ : volume of beaker used for sonication, $\mathbf{X}_{\mathbf{8}}$ : volume of cold aqueous phase

\begin{tabular}{|c|c|c|c|c|c|c|}
\hline \multirow[b]{2}{*}{ Variables } & \multicolumn{6}{|c|}{ Analysis of variance } \\
\hline & f-Value & p-Value & $\begin{array}{c}\text { R } \\
\text { square }\end{array}$ & $\begin{array}{l}\text { Adjusted } \\
\text { R squared }\end{array}$ & $\begin{array}{l}\text { Predicted } \\
\text { R Squared }\end{array}$ & $\begin{array}{c}\text { Coefficient of } \\
\text { variance }\end{array}$ \\
\hline $\begin{array}{l}\text { Average particle } \\
\text { size }\end{array}$ & 560.10 & 0.0325 & 0.9997 & 0.9980 & 0.9633 & 3.84 \\
\hline Span & 782.22 & 0.0275 & 0.9998 & 0.9985 & 0.9737 & 1.99 \\
\hline Surface area & 202.56 & 0.0541 & 0.9993 & 0.9944 & 0.8985 & 4.13 \\
\hline $\begin{array}{l}\text { Poly dispersity } \\
\text { index }\end{array}$ & 516.82 & 0.0339 & 0.9997 & 0.9978 & 0.9602 & 4.27 \\
\hline
\end{tabular}

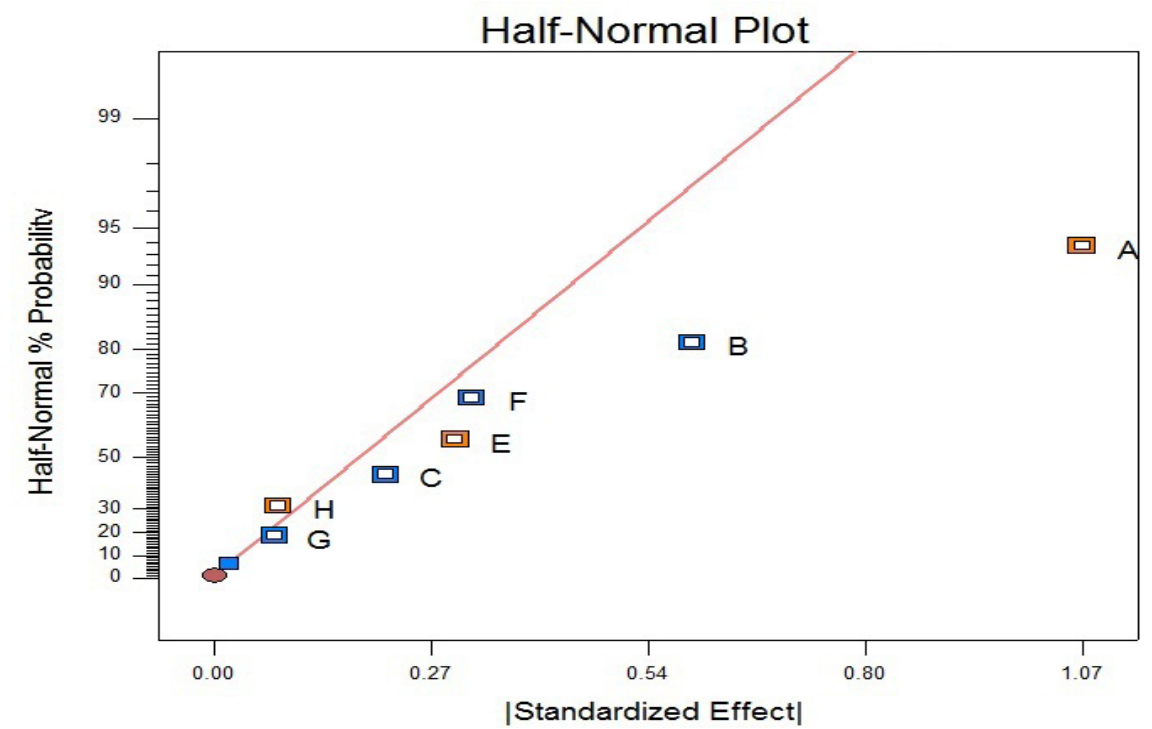

Figure 2: Particle size distribution of Rasagiline mesylate loaded solid lipid nanoparticles fabricated by microemulsion technique with lipid concentration of $50 \mathrm{mg}$, surfactant concentration of $75 \mathrm{mg}$, Co-surfactant concentration of $0.75 \mathrm{ml}$, aqueous phase volume of $5 \mathrm{ml}$, magnetic stirring speed of $400 \mathrm{rpm}$, probe soniation duration $30 \mathrm{mins}$, volume of beaker used for sonication $500 \mathrm{ml}$ and volume of cold aqueous phase $30 \mathrm{ml}$. 


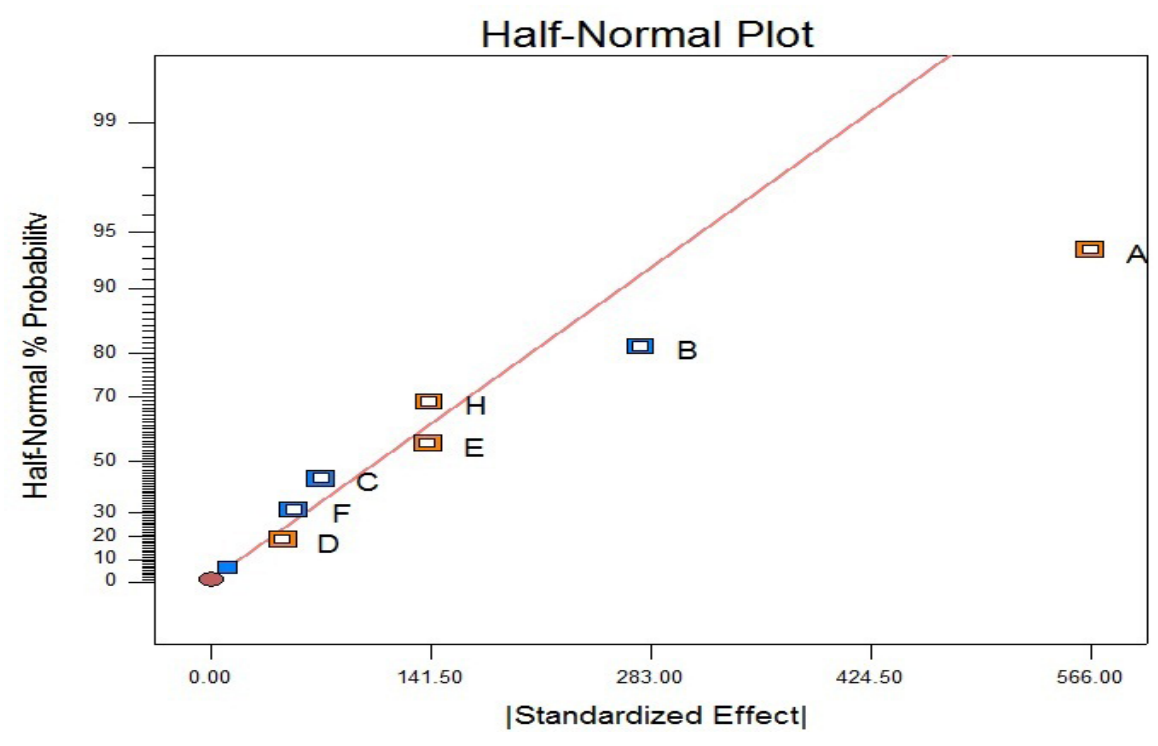

Figure 3: Plackett-Burman half normal plot for average particle size

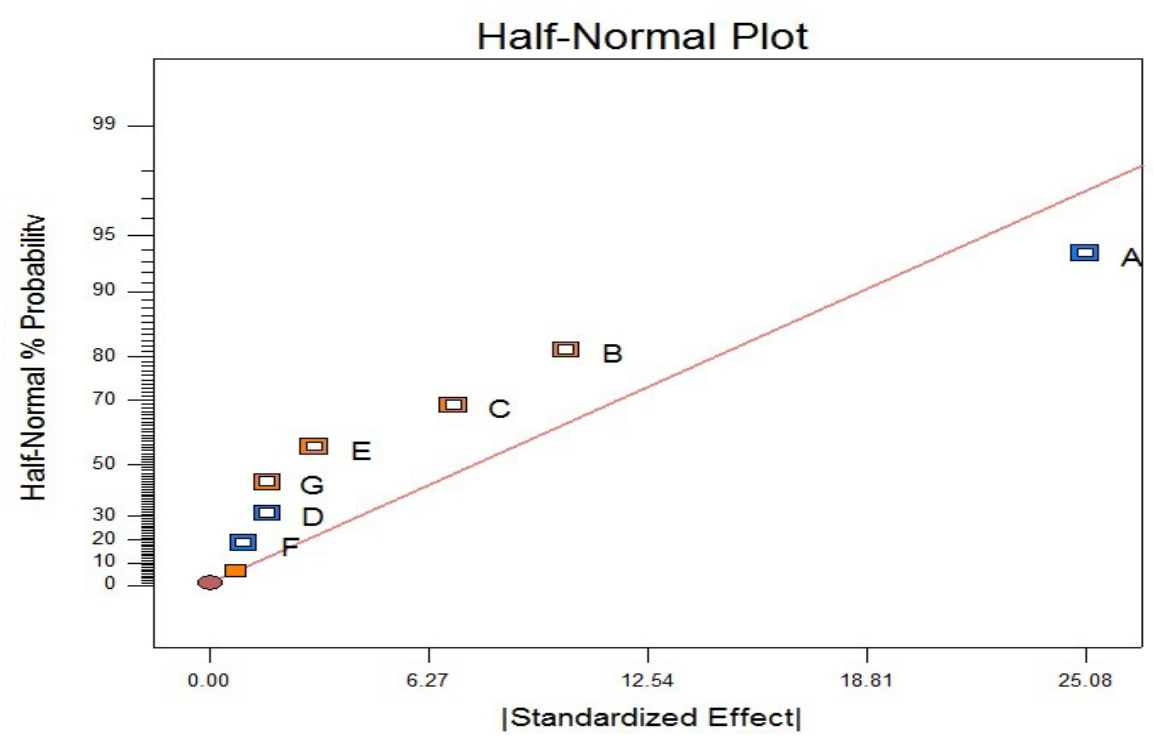

Figure 4: Plackett-Burman half normal plot for span

give a positive effect on the average particle size while surfactant concentration, co-surfactant concentration and magnetic stirrer rate give negative effect. The parameter $\left(\mathrm{X}_{7}\right)$ volume of beaker used for sonication dose not have singnificant influence on average particle size.

\section{Effect of Formulation Variables on Span}

Span is a measurement of distribution width. The fitted model describing the influence of variables on the mean span value $\mathrm{Y}_{2}$ is $[$ Span $=+1.55+0.54 * \mathrm{~A}-0.29 * \mathrm{~B}-0.11$ $* \mathrm{C}+0.15 * \mathrm{E}-0.16 * \mathrm{~F}-0.037 * \mathrm{G}+0.039 * \mathrm{H}]$ (Table 2). Where $\mathrm{Y}_{2}$ is the response=Span, A, B, C, E, F, G and $\mathrm{H}$ are concentration of lipid, concentration of surfactant, concentration of co-surfactant, magentic stirrer, probe sonicator duration, volume of beaker used probe sonication and volume of cold aqueous phase respectively with their coefficient. The obtained F-value of the model had a significant effect. The significance of $\mathrm{F}$-value and $\mathrm{R}^{2}$ $(0.9998)$ indicated that there was a good linearity between the predicted and the observed values. The predicted $\mathrm{R}^{2}$ (0.9737) and adjusted $R^{2}(0.9985)$ values implied a good correlation between the obtained and predicted value and those of the fitted models (Table 3). The adequate precision was defined as a signal to noise ratio or $\mathrm{S} / \mathrm{N}$ ratio is greater than four. Subsequently, the obtained ratio shows an adequate signal. The value of the coefficient of variation $(\mathrm{CV})$ is $1.99 \%$ and indicates the precision and reliability of the model. The main effect analysis shows, the lipid concentration, magnetic stirrer rate and volume of cold aqueous phase give positive effect on span while surfactant concentration, co-surfactant concentration, 
probe sonication duration and volume of beaker used for sonication give negative effect. The volume of aqueous phase $\left(\mathrm{X}_{4}\right)$ parameter doesn't have significant effect on span (Figure 4).

\section{Effect of Formulation Variables on Surface area}

The effect could be explained by following linear model equation $\mathrm{Y}_{3}$, [Surface area $=+31.43-12.54 * \mathrm{~A}+5.11 * \mathrm{~B}+3.49$ $* \mathrm{C}-0.82 * \mathrm{D}+1.49 * \mathrm{E}-0.47 * \mathrm{~F}+0.82 * \mathrm{G}]$ (Table 2). Where $\mathrm{Y}_{3}$ is the predicted response of surface area and A, B, C, D, $\mathrm{E}, \mathrm{F}$ and $\mathrm{G}$ are the coded values of concentration of lipid, concentration of surfactant, contration of co-surfactant, volume of aqueous phase, magentic stirrer rate, probe sonicator duration and volume of beaker used probe sonication respectively with their co-effeiceint. F-value of the model 202.56 implies that the model is not significant and the Values of "Prob > F" less than 0.0500 indicate model terms are significant (Table 3 ). The predicted $\mathrm{R}^{2}$ (0.9944) and adjusted $\mathrm{R}^{2}(0.8985)$ values implied a good correlation between the obtained and predicted value and those of the fitted models. The value of the coefficient of variation $(\mathrm{CV})$ is $4.13 \%$ and indicates the precision and reliability of the model. (Figure 5) shows the half normal plot results, the surfactant concentration, co-surfactant concentration, magnetic stirrer rate and probe sonication duration give positive effect on surface area while the lipid aqueous phase volume and probe sonication duration give negative effect. The independent variable of volume of beaker used for sonication $\left(\mathrm{X}_{7}\right)$ dose not have singnificant influence on surface area.
Effect of Formulation Variables on Poly dispersity index

The fabricated nanoparticles, size population commonly follows a multimodal distribution. The polydispersity is a significant parameter, which can provide the information about the homogeneity of the particle size and it should be $(<0.3)$. The below 0.3 of polydispersity index shows narrow size distribution and it suggest the particles are monodispersity. Following linear model equation can explain the effect of factors levels $\mathrm{Y}_{4}$, [Poly dispersity index $=+0.84+0.54 * \mathrm{~A}-.25 * \mathrm{~B}-0.083 * \mathrm{C}+0.060 * \mathrm{E}-0.031$ $* \mathrm{~F}-0.050 * \mathrm{G}+0.12 * \mathrm{H}$ ] (Table 2). Where $\mathrm{Y}_{2}$ is the response of poly dispersity index and A, B, C, E, F, G and $\mathrm{H}$ are concentration of lipid, concentration of surfactant, contration of co-surfactant, magentic stirrer rate, probe sonicator duration, volume of beaker used probe sonication and volume of cold aqueous phase respevtively with their coeffeicent. The value of the coefficient of variation (CV) is $4.27 \%$ and indicates the precision and reliability of the model (Table 3). The main effect analysis indicates lipid concentration, magnetic stirrer rate and volume of cold aqueous phase positive effect on polydispersity index while surfactant concentration, co-surfactant concentration, probe sonication duration and volume of beaker used for sonication give negative effect and the volume of aqueous phase parameters does not have significant effect on poly dispersity index (Figure 6).

The morphological photomicrograph of Rasagiline mesylate loaded solid lipid nanoparticles was evaluated by transmission electron microscopy (Figure 7a). The

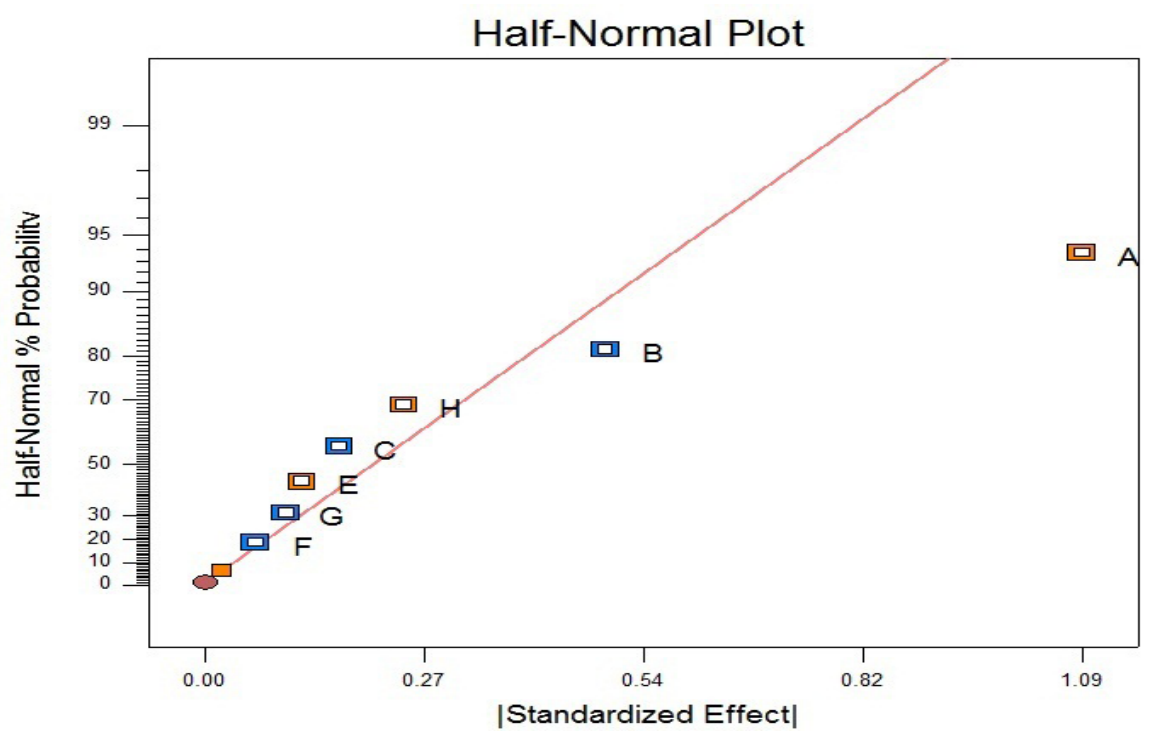

Figure 5: Plackett-Burman half normal plot for surface area 


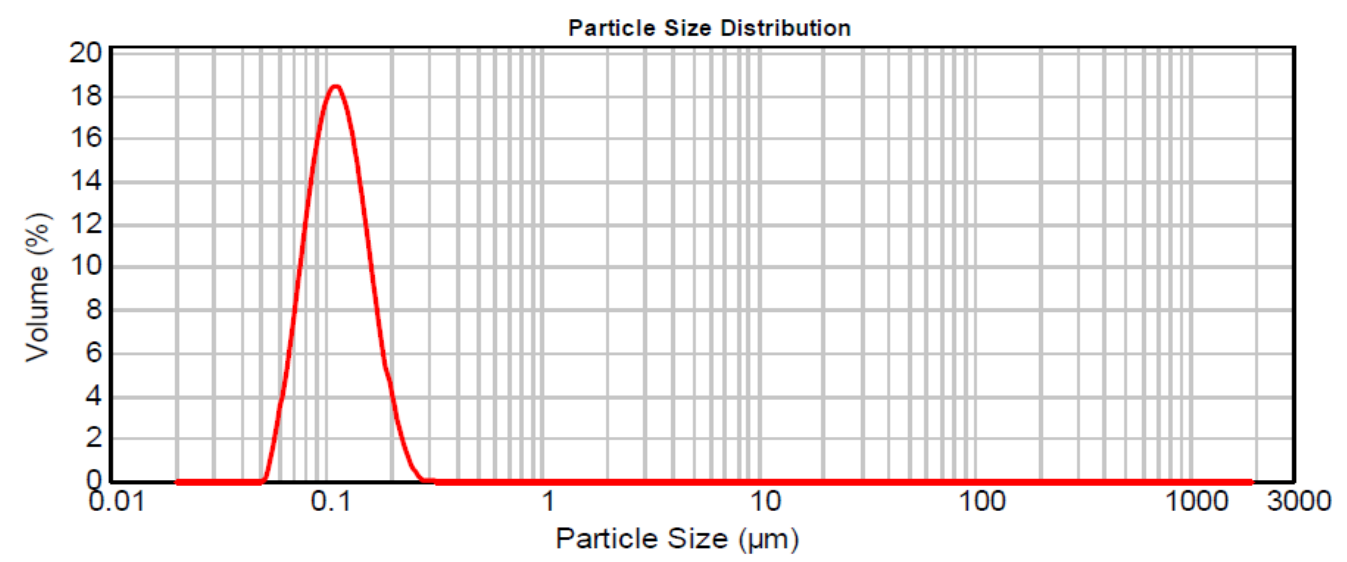

Figure 6: Plackett-Burman half normal plot for polydispersity index

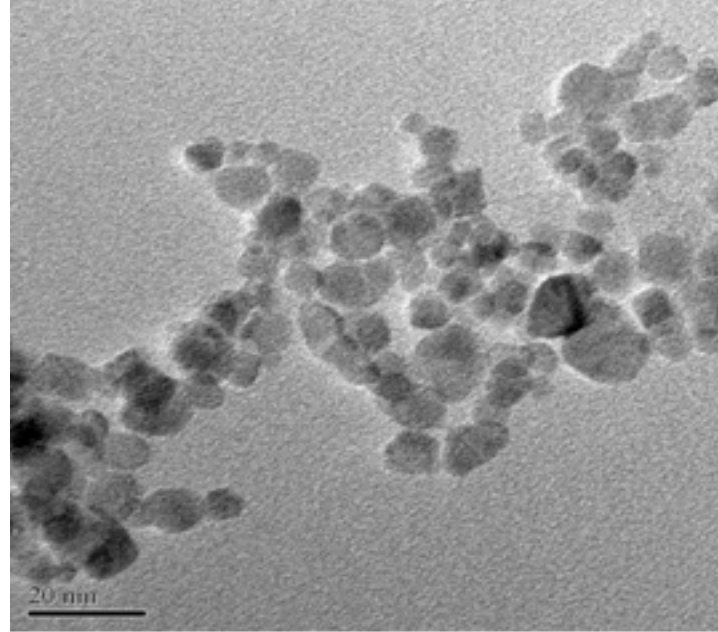

a

Figure 7: (a) Transmission electron microscopy micrograph and

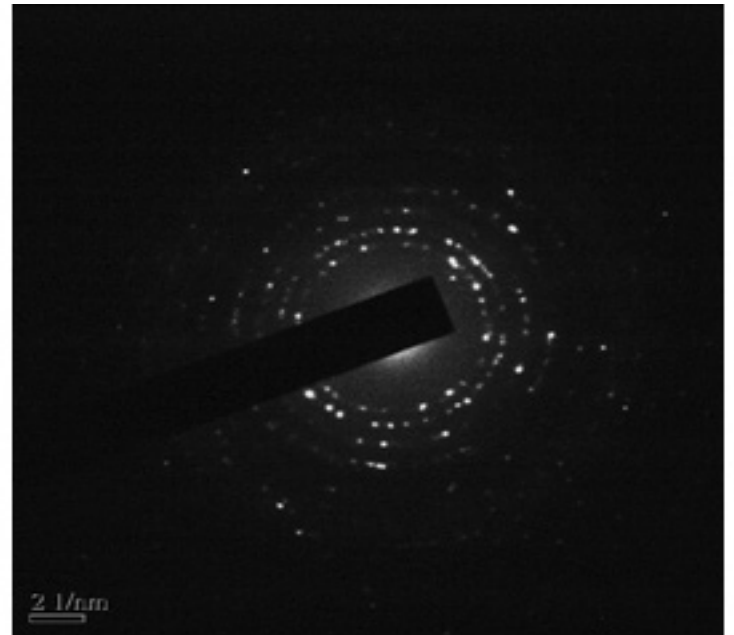

b observation of TEM shows that the RM-SLNs formulation was monodisperse, uniform size and quasispherical shape with smooth surface. (Figure 7b) shows the corresponding selected area electron diffraction (SAED) of Rasagiline mesylate loaded solid lipid nanoparticles. It obtained using the smallest selected-area aperture. The result indicates that the formulation was not in an amorphous form, it is polycrystalline structure. ${ }^{31}$

\section{CONCLUSION}

In this study, formulation and process variables on particle size, span, surface area and polydispersity index of Rasagiline mesylate loaded solid lipid nanoparticles were screened by Plackett-Burman experimental design. Based on this study, we found that the processing factor of surface area did not have significant influence on Rasagiline mesylate loaded solid lipid nanoparticles properties. Least particle size was acquired by increasing the surfactant concentration, increasing the sonication duration and decreasing the lipid concentration. The results shown that the Rasagiline mesylate-loaded solid lipid nanoparticles formulation had average mean particle size of $169 \mathrm{~nm}$ with span of 0.821 , surface area of 52.40 $\mathrm{m}^{2} \mathrm{~g}^{-1}$ and polydispersity index of 0.310 . The morphological evaluation by transmission electron microscopy was found to be monodisperse, uniform size and quasispherical shape with smooth surface by (TEM). The selected area electron diffraction (SAED) indicated the formulation was not in an amorphous form but in a crystalline state. The experimental results were good correlated with predicted data analysed by Plackett-Burman statistical method.

\section{ACKNOWLEDGEMENTS}

The authors are thankful to Department of pharmacy, 
Faculty of Engineering and Technology, Annamalai University, Annamalai Nagar, Tamil Nadu, India.

\section{CONFLICT OF INTEREST}

The authors declare that there are no conflicts of interest.

\section{Highlights of Paper}

- Parkinson's disease (PD) is the second most common, progressive degenerative disorders in the world.

- Rasagiline mesylate (RM) is a potent, non-reversible MAO-B inhibitor used for the treatment of PD.

- Nanoscale solid lipid particles method was used to improve the targeted drug delivery in a controlled manner.

- The Plackett-Burman design was successfully employed for the optimization of Rasagiline mesylate loaded Nanoscale solid lilpid particles.

- Formulation and process variables on particle size, span, surface area and polydispersity index of Rasagiline mesylate loaded solid lipid nanoparticles were screened by Plackett-Burman experimental design.

- Rasagiline mesylate-loaded solid lipid nanoparticles formulation had average mean particle size of $169 \mathrm{~nm}$ with span of 0.821 , surface area of $52.40 \mathrm{~m}^{2} \mathrm{~g}^{-1}$ and polydispersity index of 0.310 .

- The experimental results were better correlated with the predicted data analysed by Plackett-Burman statistical method.

\section{Author Profile}

- Dr.K.Kannan: Is an Assistant Professor, Department of Pharmacy, Annamalai University, Annamalai Nagar. He has over 12 years of teaching experience and his area of specialization is Pharmaceutics and Industrial pharmacy. He has supervised a number of postgraduate research students in Industrial Pharmacy of pharmaceutical dosage forms in collaboration with reputed pharmaceutical industries and currently he is supervising Ph.D scholars. His current research interest involves nanotechnology drug delivery system. He has published more than 34 review and research articles in peer reviewed journals.

\section{REFERENCES}

1. Marcos Fernandez, Sofia Negroa, Karla Slowing, Ana FernandezCarballido, Emilia Barcia. An effective novel delivery strategy of Rasagiline for Parkinson's disease. Int J Pharm. 2011; 419(1): 271-80.

2. Ravi Kumar Konda, Babu Rao Chandu, Chall BR, Chandrasekhar Kothapalli B. Bio-analytical method development and validation of Rasagiline by high performance liquid chromatography tandem mass spectrometry detection and its application to pharmacokinetic study. J Pharm Anal. 2012; 2(5): 342-9.

3. Orit Bar AM, Tamar Amit, Moussa Youdim BH. Contrasting neuroprotective and neurotoxic actions of respective metabolites of anti-Parkinson drugs Rasagiline and selegiline. Neurosci Lett. 2004; 355(3): 169-72.

4. Andreas-Antonios, Roussakis, Paola Piccini, Marios Politis. Clinical utility of DaTscan TM (123I-loflupane Injection) in the diagnosis of Parkinsonian Syndromes. Degen Neuro Neuromus Dis. 2013; 3: 33-39.

5. Jack Chen J, David Swope M, Khashayar Dashtipour. Comprehensive review of Rasagiline, a second-generation monoamine oxidase inhibitor, for the treatment of Parkinson's disease. Clin therap. 2007; 29(9): 1825-49.

6. Moussa BH Youdima, Marta Weinstock. Novel neuroprotective anti-Alzheimer drugs with anti-depressant activity derived from the anti-Parkinson drug, Rasagiline. Mech Age Devel. 2002; 123(8): 1081-6.

7. Haibin LI, Xuexhem Duan. Nanoparticles for drug delivery to the central nervous system. Nanosci. 2006; 11(3): 207-9.

8. Barnabas Wilson, Malay Kumar Samanta, Kumaraswamy Santhi, Kokilampal Perumal Sampath Kumar, Nallupillai Paramakrishnan, Bhojraj Suresh. Poly (n-butylcyanoacrylate) nanoparticles coated with polysorbate 80 for the targeted delivery of rivastigmine into the brain to treat Alzheimer's disease. Brain Res. 2008; 1200: 159-68.

9. Jifu Hao, Fugang Wang, Xiaodan Wang, Dianrui Zhang, Yanping $\mathrm{Bi}$, Yunsheng Gao, et al. Development and optimization of baicalinloaded solid lipid nano particles prepared by coacervation method using central composite design. Euro J Pharm Sci. 2012; 47(2): 497-05.

10. Robhash Kusam Subedi, Keon Wook Kang, Hoo-Kyun Choi. Preparation and characterization of solid lipid nano particles loaded with doxorubicin. Euro J Pharm Sci. 2009; 37(3): 508-13.
11. HOU Jun, ZHOU Shi-wen. New research on development of solid lipid nanoparticles. J Med Col PLA. 2007; 22(6): 385-90.

12. Wolfgang Mehnert, Karsten Mad. Solid lipid nano particles Production, characterization and applications. Adv Drug Del Rev. 2001; 47(2): 165-96.

13. Wissing SA, Kayser O, Muller RH. Solid lipid nanoparticles for parenteral drug delivery. Adv Drug Del Rev. 2004; 56(9): 1257-72.

14. Doijad RC, Manvi FV, Godhwani DM, Joseph R, Deshmukh NV. Formulation and Targeting Efficiency of Cisplatin Engineered Solid Lipid Nano particles. Ind J Pharm Sci. 2008; 70(2): 203-7.

15. Viveksarathi K, Kannan K. Multi criteria decision making to select the best method for the preparation of solid lipid nanoparticles of rasagiline mesylate using analytic hierarchy process. J Adv Pharm Tech Res. 2014; 5(3): 115-21.

16. Viveksarathi K, Kannan K. Compatibility studies of Rasagiline mesylate with selected excipients for an effective solid lipid nano particles formulation. Int J Pharm Pharm Sci. 2015; 7(1): 73-80.

17. Zhang J, Fan Y, Smith E. Experimental Design for the Optimization of Lipid Nanoparticles. J Pharm Sci. 2009; 98(5): 1813-9.

18. Ziyaur Rahman, Ahmed S. Zidan, Muhammad Habib J, Mansoor Khan A. Understanding the quality of protein loaded PLGA nanoparticles variability by Plackett-Burman design. Int J Pharm. 2010; 389(1): 186-94.

19. Dejaegher B, Dumarey M, Capron X, Bloomfield MS, Vander Heyden Y. Comparison of Plackett-Burman and super saturated designs in robustness testing. Anal Chi Act. 2007; 595(1): 59-71.

20. Hazem Ali, Irina Kalashnikova, Mark Andrew Whiteb, Michael Sherman, Erik Rytting. Preparation, characterization, and transport of dexamethasone-loaded polymeric nanoparticles across a human placental in-vitro model. Int J Pharm. 2013; 454(0): 149-57.

21. Moorthi C, Kathiresan K. Application of Plackett-Burman Factorial Design in The Development of Curcumin Loaded Eudragit E 100 Nano particles. Nano Biomed Eng. 2013; 5(1): 28-33.

22. Ahmad M, Panda BP. Screening of nutrient parameters for red pigment production by Monascus purpureus MTCC 369 under solid state fermentation by using Plackett-Burman experimental design. Chiang Mai J Sci. 2009; 36(1): 104-9. 
23. Awotwe-Otoo D, Zidan AS, Rahman Z, Habib MJ. Evaluation of anticancer drug-loaded nanoparticle characteristics by nondestructive methodologies. AAPS Pharm Sci Tech. 2012; 13(2): 611-22.

24. Kashanian S, Azandaryani AH, Derakhshandeh K. New surface-modified solid lipid nanoparticles using N-glutaryl phosphatidylethanolamine as the outer shell. Int J Nanomed. 2011; 6: 2393-01.

25. Muthu MS, Singh S. Poly (D, L-Lactide) Nanosuspensions of Risperidone for Parenteral Delivery: Formulation and In-Vitro Evaluation. Cur Drug Del. 2009; 6(1): 62-8.

26. Viveksarathi K, Kannan K. Effect of the moist-heat sterilization on fabricated nanoscale solid lipid particles containing Rasagiline mesylate. Int J Pharma Investig 2015; 5(2):1-5.

27. Rubiana M, Mainardes Raul C, Evangelista. PLGA nanoparticles containing praziquantel: effect of formulation variables on size distribution. Int J Pharm. 2005; 290(1): 137-44.

28. Allemann E, Leroux JC, Gurny R. Polymeric nano and microparticles for the oral delivery of peptides and peptidomimetics. Adv Drug Del Rev. 1998; 34(2): 171-89.

29. Jeon HJ, Jeong YL, Jang MK, Park YH, Nah JW. Effect of solvent on the preparation of surfactant-free poly (d,I lactide-co-glycolide) nanoparticles and norfloxacin release characteristics. Int J Pharm. 2000; 207(1): 99-8.

30. Soppimath KS, Aminabhavi TM, Kulkarni AR, Rudzinski WE. Biodegradable polymeric nanoparticles as drug delivery devices. J Con Rel. 2001; 70(1): 1-20.

31. Mingru Zhou, Zhiqiang Wei, Hongxia Qiao, Lin Zhu, Hua Yang, Tiandong Xia. Particle Size and Pore Structure Characterization of Silver Nano particles Prepared by Confined Arc Plasma. J Nanomat. 2009; 13(2): 1-5. 